\title{
Obituaries
}

\section{J. Trevor Silverstone, FRCPsych, FRCP, FRANZCP, DM}

Formerly Professor of Psychopharmacology and Psychiatry, St. Bartholomew's Hospital (Barts), University of London

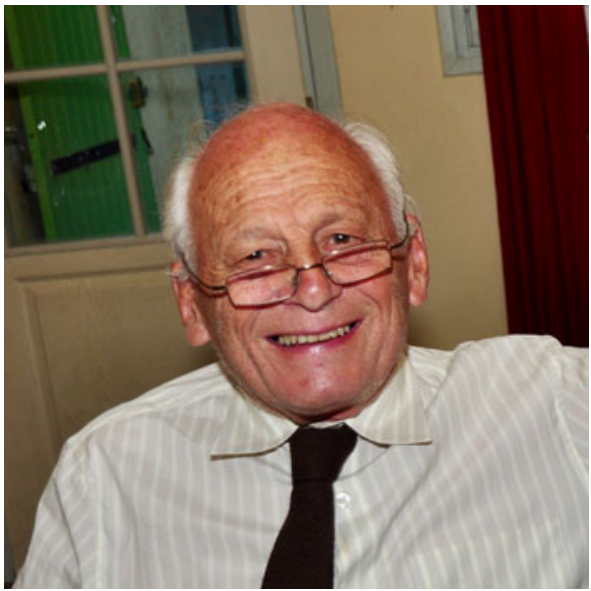

Trevor Silverstone who died on 10 January 2019 at the age of 88 years in Wellington, New Zealand, was perhaps best known for his textbook on psychopharmacology, Drug Treatment in Psychiatry. This was co-authored with his friend and colleague, the clinical pharmacologist Paul Turner (deceased, 1994), and became the standard textbook in the field in many countries. It went into five editions and was widely translated.

His main research interest in psychopharmacology was on the effect of amphetamines focused on appetite in bipolar disorder. He was innovative in his research method approaches; for example, he designed a standardised food dispenser, allowing accurate measurement of food intake over long periods. His seminal research publications were in psychological aspects of obesity, including control of appetite by medications. ${ }^{1,2}$ Trevor published widely on these and other subjects for over 35 years. His work was highly collaborative; he worked with many colleagues including John Cookson and Phil Cowen.

Trevor was born and raised in Hendon, North London. He initially went to University College School in Hampstead, but at the age of 10 he was evacuated to the USA because of the Second World War. He lived in Boston with cousins for 4 years before returning to the UK, after which he went to St. Paul's School. Following this, he won a scholarship to Hertford College, Oxford, to read medicine. After completing his undergraduate degree, he left Oxford in 1954 for the University of California, Los Angeles (UCLA) on a Fulbright Scholarship to study neurophysiology with Carmen Clemente, working on the connections between the ear and the reticular formation.
Looking back, Trevor described how he spent many happy hours 'driving around LA: up and down Sunset Boulevard (which bordered the university); to the beach where I listened to modern jazz at a place called "The Lighthouse"; and in and out of Beverly Hills'. After his time at UCLA he returned to London to obtain his medical degree at St. Bartholomew's Hospital.

Trevor had long decided to specialize in psychiatry. After house physician and surgical appointments, and passing his MRCPsych examinations, he joined the psychiatry training programme at the Maudsley Hospital in 1961. There, he worked on the Professorial Unit under the famed (and feared)

Professor Sir Aubrey Lewis, part of the time in the unit run by Dr (later Professor) Gerald Russell - an experience that I, much later, shared with him. After completing his training at the Maudsley in 1964, Trevor moved to the University of Pennsylvania to do research, working with Professor Albert (Mickey) Stunkard who was one of the global leaders in research on obesity and eating disorders. There, he worked particularly on the role of dextroamphetamine on appetite, a subject that formed the basis for his MD thesis. It was while in the USA that Trevor developed his passion for research into appetite, which was to remain with him throughout his life.

After returning to England in 1965, he was appointed Senior Lecturer in the Department of Psychological Medicine at St. Bartholomew's Hospital, where he remained for 27 years. He was promoted to Reader in 1985, and Professor of Clinical Psychopharmacology and Head of Department in 1989. During his time at Barts, he was an active researcher, publishing over 120 peer-reviewed articles and authoring 6 books. He lectured widely all over the world, enjoying the opportunity to meet friends and colleagues in many different places.

Trevor was a highly regarded lecturer, in demand both as a speaker and chairperson of academic seminars. He was also well known for his wit and communication abilities as a moderator and raconteur. He greatly enjoyed educating junior colleagues including medical students, psychiatric trainees, $\mathrm{PhD}$ students and other professionals.

He retired from Barts in 1991 to move to New Zealand, where he did both research and clinical work for over a decade. He served as Clinical Director of Mental Health Services for the local District Health Board in Dunedin. In 2002 he moved to Toronto, Canada, and continued to write. He published his final book, Drugs in the Treatment of Disorders of Appetite and Body Weight, after he had retired.

For many years after retirement, Trevor was able to indulge his passions of food, art and music. However, with increasing health problems and finding the Canadian winters difficult, he and his second wife Sarah Romans returned to New Zealand in 2009. His health began to deteriorate significantly in 2014.

Trevor was married to Rosalie Ann Silverstone from 1957 until their divorce in 1989, and he married Sarah in 1995. He is survived by his wife Sarah, and by his two sons and five grandchildren from his first marriage. 


\section{References}

1 Silverstone JT, Stunkard AJ. The anorectic effect of dexamphetamine sulphate. Br J Pharmacol Cheomther 1968; 33: 513-22.

2 Emelie JL, Silverstone JT, Mann LI, Williams SM, Romans SE. Prevalence of overweight and obesity in bipolar patients. J Clin Psychiat 2000; 61 $179-84$

Peter H. Silverstone peter.silverstone@me.com

doi:10.1192/bjb.2019.41

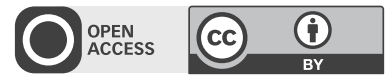

(c) The Author 2019. This is an Open Access article, distributed under the terms of the Creative Commons Attribution licence (http://creativecommons.org/ licenses/by/4.0/), which permits unrestricted re-use, distribution, and reproduction in any medium, provided the original work is properly cited.

\section{Peter Bruggen, MB ChB FRCPsych}

\section{Formerly Consultant Adolescent Psychiatrist, Hill End Adolescent Unit, St. Albans, Hertfordshire}

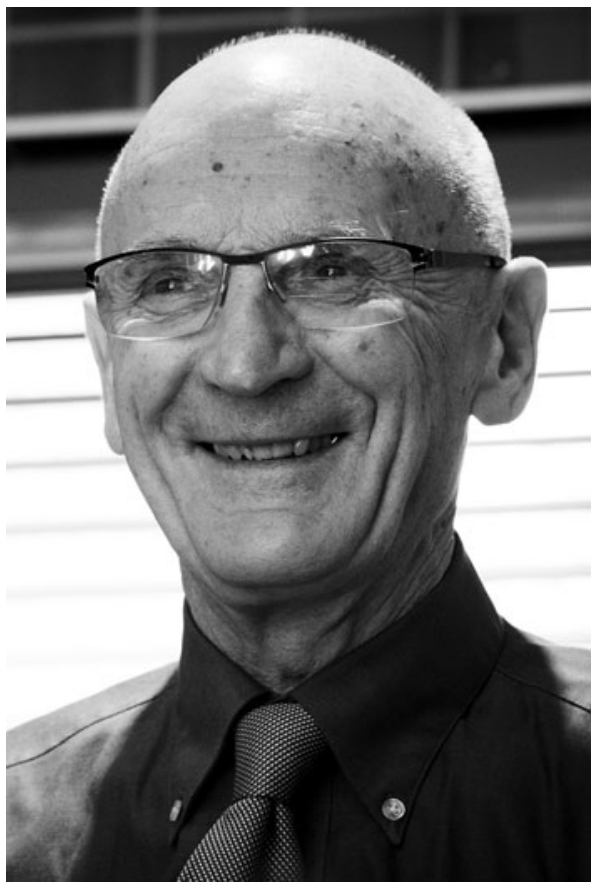

Peter Bruggen, who died in September last year at the age of 84 , developed what was at the time a unique systemic model for managing an in-patient adolescent unit. Admission, Peter believed, resulted from the inability of patient's support systems to cope with the anxiety caused by the patient's behaviour. Medical diagnosis was eschewed in favour of a systemic behavioural formulation. Peter was sensitive to the adverse effects of institutional care and actively sought to prevent admission, or, when inevitable, to keep admission as short as possible. At initial meetings in the community, he and the team often successfully helped to find alternatives to admission. Young people were admitted only if there was nowhere else which could keep them safely.

Admission enhanced parents' authority by making explicit their right to admit their teenager (under 16) to a place of safety. Discharge was predicated on the young person demonstrating, on weekly home visits, their commitment to change by achieving precisely defined, positively framed 'minimum changes', agreed at the admission meeting with the parents (or care-holders). To discourage institutional or dyadic dependencies, all psychotherapeutic work was done in groups (family, 'community' encounter-style and/or 'action' groups) and there were no 'home comforts'. Boundaries were strictly enforced, and staff immediately confronted adolescents in ad hoc 'community' meetings about any anxiety-provoking behaviour. Adolescents in turn were encouraged and enabled to be open and honest with themselves and others, to call meetings, to take responsibility for their actions and the consequences of their actions, to understand their power and its limits, to explore their difficulties and find solutions in innovative 'action' groups, and to work to get out of hospital as soon as possible. The austere and non-nurturing atmosphere, and the ways that behaviour was challenged (with community meetings, seclusion and, if all else failed, with sedation) was felt by some young people to be abusive (and indeed recent allegations of historical abuse are currently the subject of a police investigation). However, the transformations for the majority of young people and their families (at least in the short term) were impressively quick, empowering of parents and adolescents, and often restored hope which had previously been lost. Although Peter was explicit about his role and responsibility as the lead clinician, the staff group culture was egalitarian with a strong personal development ethic, and Peter was an enthusiastic advocate for interdisciplinary working. Peter emphasised the contribution of the professional team to the model developed, but it was clear to all that Peter was the instigator of much of the radical thinking, the integrator, the one who made it happen.

Peter will be remembered as a man of principle and purpose, a clear, independent and creative thinker, who challenged the very way in which we understood mental illness and its manifestations. He was a warm, open, honest and humble man, as well as a charismatic leader. He stood up against the conventional when it clashed with his strongly held ethical values, refused military service as a conscientious objector, was an activist marching for the Campaign for Nuclear Disarmament, and was a lifelong member of the Labour Party. He traced his enduring enthusiasm for new ways of thinking to sessions he had in the early 1960s of the then-pioneering LSD-augmented psychotherapy.

Qualifying as a doctor in Edinburgh in 1957, he did his training in psychiatry at Warlingham Park Hospital, where he became interested in psychotherapy, had a training analysis with Marion Miller, and joined the Tavistock Clinic, first as a Senior Registrar under Derek Miller and with supervision by Donald Winnicott (he traced his clear thinking about the use of authority to these two mentors), and then as a Consultant in the Adolescent Department. However, by the time of his deployment to Hill End in 1969, he had become more interested in the new, 